\title{
Development and Clinical Evaluation of a Root Coverage Procedure Using a Collagen Barrier Membrane
}

\author{
An-Tay Shieh, ${ }^{*}$ Hom-Lay Wang, ${ }^{\dagger}$ Robert $O^{\prime}$ Neal,${ }^{\ddagger}$ Gerald N. Glickman, ${ }^{\S}$ and \\ R. Lamont MacNeil ${ }^{\dagger}$
}

THE USE OF GUIDED TISSUE REGENERATION (GTR) procedures in the treatment of gingival recession has shown promising results and is gaining clinical acceptance. The purpose of this study was to assess the use of a bioabsorbable collagen membrane as a barrier device in root coverage treatment of gingival recession defects. The study consisted of 10 patients with 10 defects of either Miller Class I or II description and gingival recession $\geq 2.5 \mathrm{~mm}$. Clinical measurements taken at baseline included plaque index (PI) and gingival index (GI), clinical attachment level (CAL) measured with an automated probe and reference stent, recession depth $(\mathrm{RD}$; mean $=3.19 \pm 0.26 \mathrm{~mm})$, recession width $(\mathrm{RW} ; 3.95 \pm 0.41$ $\mathrm{mm}$ ), probing depth (PD; $2.3 \pm 0.2 \mathrm{~mm}$ ), and width of keratinized tissue (KT; $2.4 \pm 0.3$ $\mathrm{mm}$ ); measurements were repeated at 1,2 , and 4 weeks and 3 and 6 months post-treatment. During the surgical procedure, a mucoperiosteal flap was elevated and the respective root thoroughly planed. The collagen membrane was cut to cover the defect and surrounding bone, positioned over the root, and secured with 5-0 gut interdental sutures. The flap was coronally positioned to cover the membrane and sutured with 5-0 silk. Data were analyzed using the Student paired $t$-test to compare pre- and postsurgery measurements. The nonparametric Wilcoxon matched pairs test was used to analyze the significance of PI and GI at different time intervals. A statistically significant $(P<0.01)$ reduction in $\mathrm{RD}(-1.66 \pm 0.25 \mathrm{~mm})$ was observed at 6 months, representing $51.6 \%$ total attainable root coverage. Clinically, a statistically significant mean gain of $1.34 \pm 0.47 \mathrm{~mm}$ CAL and $0.90 \pm 0.32 \mathrm{~mm} \mathrm{KT}$ was observed at 6 months. No statistical differences were found in PD and RW between baseline and 6 months postoperatively. PI and GI remained low and showed no statistically significant change $(P<0.05)$ throughout the study period. Results from this study suggest that a collagen membrane can be used successfully as a barrier device in GTR-based root coverage procedures. J Periodontol 1997;68:770-778.

Key Words: Gingival recession/surgery; gingival recession/therapy; guided tissue regeneration; collagen/therapeutic use; esthetics, dental; membranes, barrier.

Predictable coverage of exposed root surfaces and the corresponding correction of gingival recession defects remain important aspects of periodontal therapy. A variety of techniques have been developed over the past few decades to handle this common clinical problem. Traditional surgical

*Previously, Department of Periodontics/Prevention/Geriatrics, School of Dentistry, University of Michigan; currently, private practice, Taipei, Taiwan.

'Department of Periodontics/Prevention/Geriatrics, School of Dentistry, University of Michigan, Ann Arbor, MI.

\#reviously, Department of Periodontics/Prevention/Geriatrics, School of Dentistry, University of Michigan; currently, Department of Periodontics, School of Dentistry, University of Washington, Seattle, WA.

Department of Cariology, Restorative Sciences, and Endodontics, School of Dentistry, University of Michigan, Ann Arbor, MI. approaches such as the laterally positioned flap, ${ }^{1,2}$ free gingival graft, ${ }^{3,4}$ connective tissue graft, 5,6 and coronally positioned flap ${ }^{7}$ have been shown to be relatively successful in achieving root coverage. Recently, attempts have been made to achieve root coverage using surgical techniques based on the principles of guided tissue regeneration (GTR). ${ }^{8-17}$ These procedures have employed a variety of occlusive barrier products including nonabsorbable (e.g., expanded polytetrafluoroethylene) and bioabsorbable (e.g., polylactic or polyglycolide polymer) materials.

When compared to other root coverage procedures, GTR therapy offers an additional benefit through its potential of achieving new attachment formation along the previously denuded root surface. For example, the type 


\section{CLINICAL PARAMETERS}

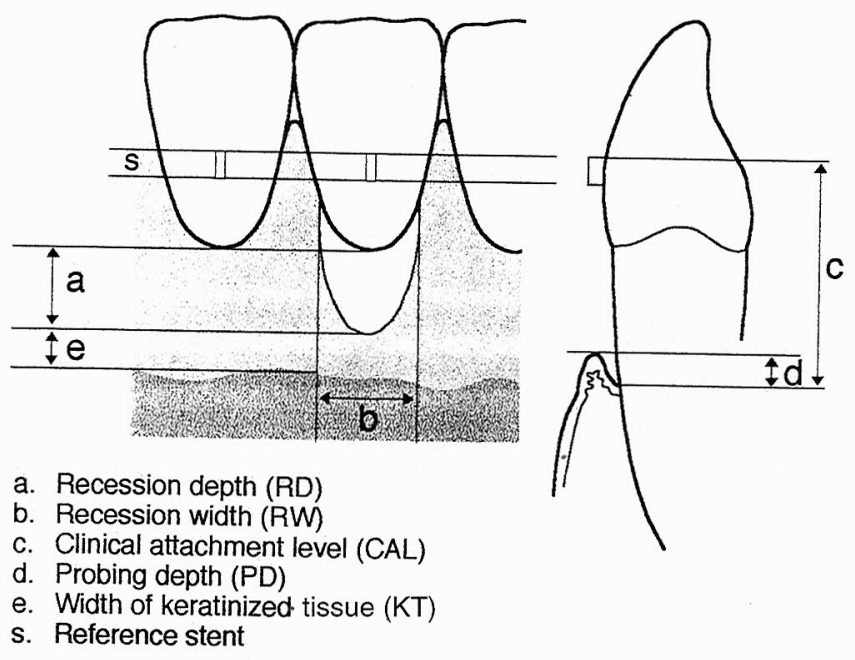

Figure 1. Diagram to indicate all clinical parameter measurements.

of healing observed following transposition of a pedicle graft is usually formation of a long junctional epithelium with a minimal amount of new connective tissue attachment. ${ }^{18,19}$ In comparison, GTR-treated sites typically show healing characterized by varying amounts of new bone, new cementum, and new periodontal ligament. ${ }^{20,21}$ It appears then that GTR therapy is a legitimate approach toward managing the problem of root coverage, and clinical outcomes may be even more favorable than that achieved with traditional methods.

Until recently, GTR procedures have used non-absorbable expanded polytetrafluoroethylene (ePTFE) barrier materials." Tinti et al. treated 12 recession defects with an ePTFE membrane and reported an average of $52 \%$ root coverage. ${ }^{9}$ When comparing the GTR-based root coverage procedure to use of free gingival grafts with coronally positioned flaps in an attempt to cover gingival recession defects, a similar amount of root coverage $(72.73 \%$ vs. $70.87 \%$ ) was attained. These first generation materials have proven to have great utility in GTR therapy; however, they also suffer from a number of clinical and biological deficiencies including the need for a secondary surgical procedure to remove the material at the end of the healing phase. These deficiencies have led to a search for alternative, second-generation materials which are occlusive but also bioabsorbable and "tissue-friendly." A number of naturally-absorbable materials, including synthetic polymers and animal-derived collagen products, have been introduced as GTR barriers over the past decade. In clinical testing, these materials have shown re-

"Gore-Tex Periodontal Material, W.L. Gore \& Associates Inc., Flagstaff, AZ. sults comparable to traditional non-absorbable barrier materials in the treatment of intrabony, ${ }^{22,23}$ furcation, ${ }^{24,25}$ and dehiscence ${ }^{26,27}$ defects.

Clot stabilization, wound stability, space provision, epithelial cell exclusion, and primary gingival coverage have been demonstrated as important factors determining tissue regeneration/repair when barrier techniques are used. ${ }^{28-29}$ Barriers composed of type I collagen may have advantages over traditional materials in achieving many of these wound healing requirements. Collagen is the predominant protein in human connective tissue including periodontal tissues and, as such, should be well-tolerated by gingival tissue and incorporated as a native structure. Through its ability to aggregate platelets, collagen has been shown to act as a hemostatic agent which promotes initial clot formation and wound stability..$^{30}$ Membranes composed of collagen have been shown to act as barriers which not only provide space for potential regeneration but also preclude epithelial cell migration..$^{31,32}$ In addition, as a material which is chemotactic for fibroblasts, collagen may better facilitate cell migration over the GTR barrier during the early phase of flap healing ${ }^{33}$ when compared to other devices. These properties may reduce the incidence of membrane exposure and bacterial contamination, two sequelae which are known to inhibit tissue regeneration. It is also possible that collagen barriers may act similarly to subepithelial connective tissue grafts by providing a collagenous scaffold for tissue repair and may secondarily augment the volume (thickness) of gingival tissue following in vivo expansion, enzyme degradation and eventual replacement by the surrounding connective tissue. ${ }^{27}$ Barriers composed of collagen also appear to exhibit low antigenicity. Johns et al. indicated that collagen membranes placed during GTR procedures do not elicit an antibody reaction. ${ }^{34}$ Wang et al., in a GTR study, further reported an absence of localized hypersensitivity reactions at sites of collagen membrane placement. ${ }^{31}$ The apparent low antigenicity of these products is likely related to the fact that commercial collagen material is typically treated with pepsin to remove its most highly antigenic portion, tyrosine. Overall, collagen membrane appears to be a biocompatible and safe material for use in GTR. These properties collectively make collagen attractive for use in GTR-based root coverage procedures. Therefore, the purpose of this study is to evaluate the use of a collagen membrane for the treatment of gingival recession defects.

\section{MATERIALS AND METHODS}

\section{Subjects}

The research protocol herein described was approved by the university committee governing use of human subjects in clinical experimentation. Ten systemically healthy patients ( 5 males and 5 females; 21 to 70 years of age; mean 


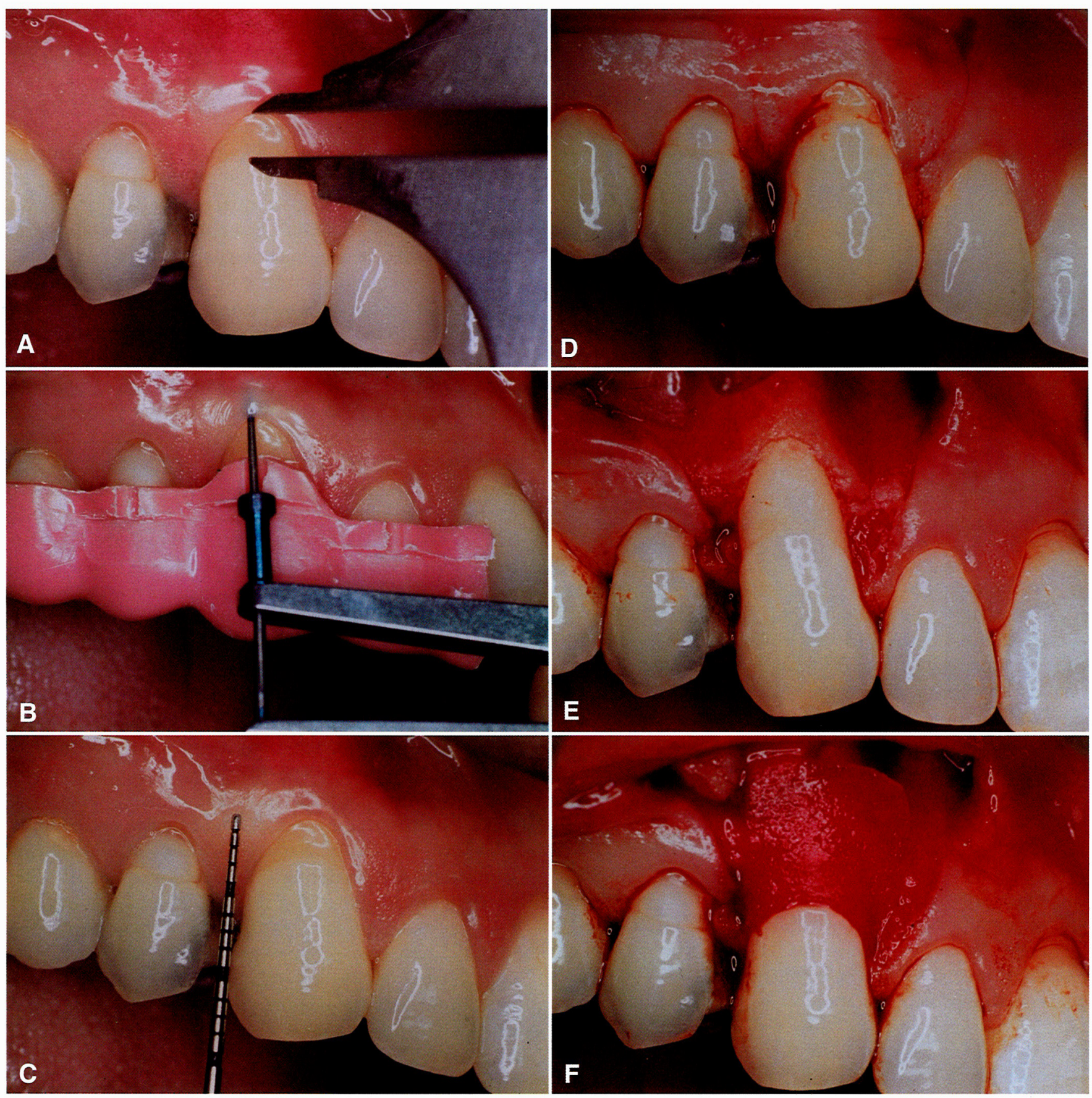

Figure 2. Illustrated collagen membrane GTR-based root coverage surgical procedure. A) Baseline, recession depth recorded using a Boley gauge; B) Baseline, clinical attachment level measurement with an automated probe and a reference stent; C) Baseline, initial buccal gingival recession (2.9 $\mathrm{mm})$ with a North Carolina probe; $\boldsymbol{D})$ Two diverging vertical incisions are made on the distal and mesial papillae of the tooth, extending beyond the mucogingival junction (MGJ). An intrasulcular incision is then made to connect the two vertical releasing incisions; $\boldsymbol{E}$ ) A trapezoidal full-thickness mucoperiosteal flap is reflected above the MGJ. Sharp dissection is utilized beyond the MGJ to free the flap from tension. The epithelium of the interproximal papilla is removed by sharp dissection to provide a bleeding connective tissue bed. The exposed root surface is then thoroughly planed and recontoured by curets and/or rotary burs to remove plaque and reduce root prominence; $\boldsymbol{F}$ ) The collagen membrane is custom-trimmed and positioned over the root surface to extend 2 to $3 \mathrm{~mm}$ beyond the bony margin. The barrier is secured in position with 5 -0 interdental gut sutures. 

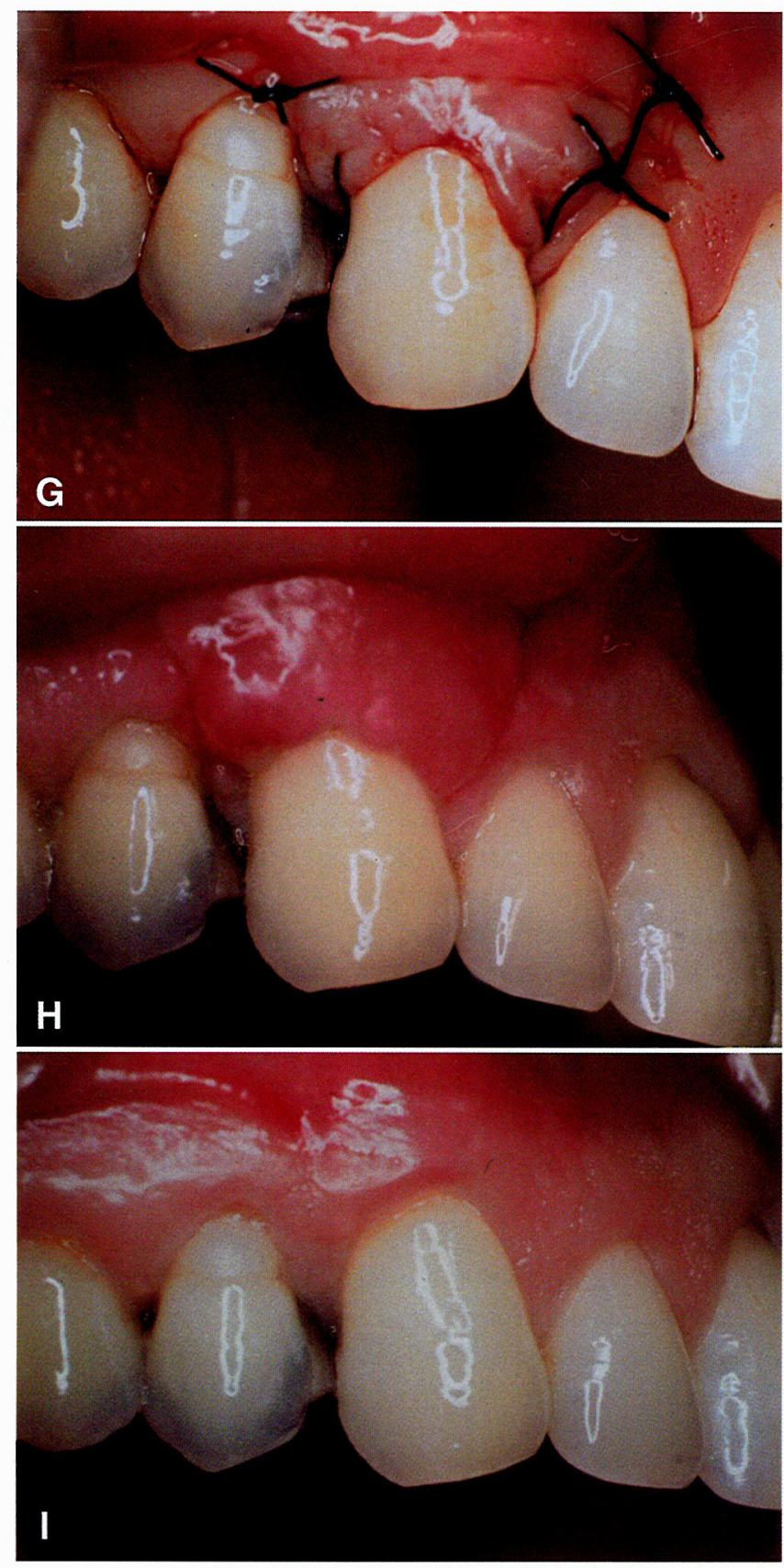

Figure 2. Continued. G) The gingival flap is coronally positioned to cover the collagen membrane and secured with 5-0 silk or gut sutures at the mesial and distal angles; $\boldsymbol{H})$ One week post-surgery, healing is uneventful; I) Six months post-surgery, 100\% root coverage is achieved.

age 40.7 years) were selected from the patient pool of the Graduate Periodontic Clinic at the University of Michigan School of Dentistry. Patient selection criteria for this clinical study included: 1) Miller's Class I or II buccal gingival recession $\geq 2.5 \mathrm{~mm}$; 2) radiographic evidence of sufficient interdental bone (the distance between crestal bone and CEJ $\leq 2 \mathrm{~mm}$ ); 3) absence of antibiotic use within the last 6 months; 4) absence of mucogingival surgery within the last 12 months; 5) evidence of patient's ability to perform good plaque control; and 6) lack of any known allergic response to collagen products. Written informed consent was obtained from each participant prior to initiation of the study. The teeth selected and treated for the study included 3 mandibular incisors, 1 mandibular bicuspid, 1 mandibular molar and 5 maxillary cuspids.

\section{Measurements (Figure 1)}

All measurements were performed by one examiner (AS). Prior to the study, the examiner was calibrated to reduce intra-examiner error (Kappa > 0.75). At baseline; at 1, 2, and 4 weeks; and at 3 and 6 months postsurgery, the participants were evaluated using the following clinical parameters: recession depth (RD), recession width (RW) at level of cemento-enamel junction, width of keratinized tissue (KT), plaque index (PI), and gingival index (GI). Clinical attachment level (CAL) and probing depth (PD) were recorded only at baseline and 6 months. For reference, similar measurements were taken from the mesiobuccal site of an adjacent non-treated tooth. At 6 months post-treatment, the percentage of root coverage was calculated according to the following formula:

(postoperative recession depth - preoperative recession depth)/preoperative recession depth $\times 100 \%$

PD was measured on three aspects (mesio-, mid- and disto-buccal) to the nearest millimeter using a North Carolina probe; depths were recorded from the free gingival margin to the apical end of the sulcus. CAL was measured from reference points (reference stent) to the apical end of the sulcus by using an automated probe with a constant force set at 20 grams. KT was measured from the CEJ to the free gingival margin using a North Carolina probe. $\mathrm{RD}$ was measured from the $\mathrm{CEJ}$ to the free gingival margin at the deepest site by using a Boley gauge (measured accurately to $\pm 0.1 \mathrm{~mm}$ ). RW was obtained by measuring the horizontal dimension of the gingival defect at the level of the CEJ by a Boley gauge. PI was recorded according to Silness and Löe. ${ }^{35}$ GI was measured using the criteria described by Löe. ${ }^{36}$

\section{Surgical Protocol (Figure 2, A-I)}

All surgical procedures were performed by one surgeon and supervised by two experienced faculty members over a 13-month period. Following local anesthesia, an intrasulcular incision and two diverging vertical releasing incisions (i.e., one mesial and one distal) extending beyond the mucogingival junction (MGJ) were made on the buccal aspect of the involved tooth. The adjacent marginal gingiva was left undisturbed by placing the vertical incision at least $0.5 \mathrm{~mm}$ away from the adjacent tooth surface. A trapezoidal mucoperiosteal flap was elevated to the level of the mucogingival junction. In the area apical to the MGJ, partial-thickness dissection was employed. In 
Table 1. Demographic Information of Individual Treated Sites (mm) at Baseline; 1, 2, and 4 Weeks; and 3 and 6 Months Postoperatively $(n=10)$

\begin{tabular}{lcccccc}
\hline Subject & Baseline & 1 Week & 2 Weeks & 4 Weeks & 3 Months & 6 Months \\
\hline CM & 3.2 & 0.3 & 1.4 & 1.6 & 2.0 & 2.1 \\
KW & 3.4 & 1.4 & 3.2 & 2.5 & 2.2 & 2.0 \\
MH & 2.8 & 1.0 & 0.5 & 0.5 & 0.4 & 0.0 \\
MK & 2.9 & 0.0 & 0.0 & 0.4 & 1.0 & 1.0 \\
MR & 2.5 & 1.3 & 1.0 & 1.7 & 1.9 & 1.8 \\
MS & 2.5 & 0.0 & 0.5 & 0.9 & 1.2 & 1.1 \\
PR & 3.9 & 1.6 & 2.6 & 2.7 & 2.1 & 2.1 \\
SL & 5.2 & 0.3 & 1.3 & 1.4 & 2.0 & 2.1 \\
TD & 3.0 & 1.6 & 1.6 & 2.5 & 1.6 & 1.3 \\
WH & 2.5 & 0.9 & 1.1 & 1.1 & 1.6 & 1.8 \\
Mean \pm SE & $3.19 \pm 0.26$ & $0.84 \pm 0.20^{*}$ & $1.32 \pm 0.31^{*}$ & $1.53 \pm 0.26^{*}$ & $1.60 \pm 0.18^{*}$ & $1.53 \pm 0.22^{*}$ \\
$P$ & & 0.0001 & 0.0002 & 0.0005 & 0.0001 & 0.0001 \\
\hline
\end{tabular}

Standard error $(\mathrm{SE})=$ standard deviation $/ \sqrt{10}$.

*Significant change from baseline $(P<0.01)$.

the adjoining interdental papillae, gingivoplasty was performed to remove the epithelium and provide a bleeding connective tissue bed for the future coronally positioned flap. The exposed root surfaces were thoroughly planed and contoured by curets and/or rotary burs to remove plaque and reduce the root prominence. The collagen membrane used heret is an FDA-approved absorbable barrier product composed of purified crosslinked bovine Achilles type I collagen and differs from other membranes using collagen procured from the skin and containing both type I and III collagen.\#** The collagen barrier material was subsequently custom-cut, positioned over the root coronally to the CEJ with 2 to $3 \mathrm{~mm}$ beyond the bony margin, and secured with 5-0 interdental gut sutures. Any excessive tissue was trimmed from the flap. The flap was then coronally positioned to cover the membrane and secured with two 5-0 silk or gut sutures at the mesial and distal angles, respectively. Care was taken to ensure that the flap was free of tension. Periodontal dressing was used to protect the operated site from any potential trauma. After surgery, routine written and oral postoperative care instructions were given to the patients. Antibiotics were not prescribed unless signs or symptoms of infection developed postsurgically. Oral hygiene techniques were performed only in the quadrants without surgery during the first postsurgery month. Patients were instructed to rinse twice daily with $0.12 \%$ chlorhexidine gluconate $^{t \dagger}$ mouthrinse for a period of 2 to 4 weeks after the first postoperative week. Patients were seen at 1,2 , and 4 weeks and 3 and 6 months for postoperative care and clinical measurements. Dressing materials and sutures were removed at 7 to 10 days after surgery. Professional prophylaxis without prophy paste and reinforcement of oral hygiene instructions were also performed if indicated

"BioMend, Calcitek Inc., Carlsbad, CA.

"Periogen, Collagen Inc., Palo Alto, CA.

**ParoGuide, Coletica, Lyon, France.

${ }_{\ddagger}^{\dagger}$ Peridex, Procter \& Gamble, Cincinnati, $\mathrm{OH}$. (i.e., visible supragingival plaque or calculus present) at each post-treatment visit.

\section{Statistical Analysis}

Prior to the initiation of the study, a statistical power analysis was used to determine the sample size. Estimated standard deviation of the population was assumed as 0.7 $\mathrm{mm}$ (from a previous study), ${ }^{14}$ while the minimum difference (between pre- and post-treatment status) was set at $1 \mathrm{~mm}$ for detecting significance. When $\alpha$ (the probability of type I error) $=0.05$, and $\beta$ (the probability of type II error) $=0.20,8$ subjects would be the minimally allowed subject size to achieve an $80 \%$ chance for detecting a statistical difference. The data were organized, presented as means \pm standard error, and analyzed using a statistical software program. ${ }^{\ddagger \ddagger}$ Student's paired $t$-test was used to compare pre- and postsurgery measurements. The nonparametric Wilcoxon matched pairs test was used to analyze the significance of PI and GI at different time intervals. Significance was reported at the $95 \%$ confidence level.

\section{RESULTS}

Table 1 describes demographic information for all treated sites and associated outcomes. At presurgery, the mean recession depth was $3.19 \mathrm{~mm}$ (ranged from 2.5 to 5.2 $\mathrm{mm})$. A statistically significant reduction $(P<0.01)$ of RD was observed after treatment, which was maintained throughout the experimental period (Table 2). A mean reduction of $1.66 \pm 0.25 \mathrm{~mm}$ in $\mathrm{RD}$ was noted at 6 months postoperatively. At 1 week after treatment, a mean of $72.56 \%$ of root coverage was observed, which then decreased as the follow-up time elapsed. However, no statistically significant changes occurred after 4 weeks. At 6 months, the total root coverage was reduced to $51.55 \%$ (ranging from $28 \%$ to $100 \%$ ) (Table 3). Five sites 
Table 2. Clinical Parameters of Treated Sites (mm; mean \pm standard error) at Baseline and 6 Months Postoperatively $(n=10)$

\begin{tabular}{lccc}
\hline & Baseline & 6 Months & $\begin{array}{c}\text { Difference } \\
\text { (6 Months- } \\
\text { Baseline) }\end{array}$ \\
\hline Recession depth & $3.19 \pm 0.26$ & $1.53 \pm 0.22$ & $-1.66 \pm 0.25^{*}$ \\
Recession width & $3.95 \pm 0.41$ & $3.24 \pm 0.52$ & $-0.71 \pm 0.56$ \\
$\begin{array}{l}\text { Keratinized tissue } \\
\text { Change in clinical } \\
\text { attachment level }\end{array}$ & $9.40 \pm 0.30$ & $3.30 \pm 0.40$ & $0.90 \pm 0.32^{*}$ \\
Probing depth & $1.60 \pm 0.43$ & $7.70 \pm 0.34$ & $-1.34 \pm 0.47^{*}$ \\
& & $1.60 \pm 0.30$ & $0.00 \pm 0.21$ \\
\hline
\end{tabular}

* Statistically significant difference $(P<0.05)$.

achieved more than $50 \%$ root coverage, while one site demonstrated complete root coverage.

RW was significantly reduced $(P<0.01)$ at 1 and 2 weeks after surgery. A rebound of RW was noted at 4 weeks postsurgery and showed no statistical difference when compared to baseline measurements. At 6 months postsurgically, a mean reduction of $0.7 \mathrm{~mm} \mathrm{RW}$ was observed (Table 2).

A statistically significant $(P<0.05)$ mean gain of 1.34 $\pm 0.47 \mathrm{~mm}$ of CAL was noted at 6 months after treatment. However, no significant change of PD was noted before and after treatment (Table 2). A significant increase of KT was found at 1 week and 6 months postoperatively $(P<0.05)$. A gain of $0.9 \mathrm{~mm}$ of $\mathrm{KT}$ was observed at the end of the study (Table 2).

There was no significant difference between GI and PI when treated test sites were compared to the adjacent nontreated sites (Table 4). In addition, GI and PI remained low and showed no statistical difference throughout the experimental period. However, a slight increase of GI and PI at 2 and 4 weeks was noted.

Adjacent sites did not demonstrate statistically significant changes in any clinical parameters during the study.
Table 5. Clinical Parameters of Non-Treated Adjacent Sites (mm; mean \pm standard error) at Baseline and 6 Months Postoperatively $(\mathbf{n}=\mathbf{1 0})$

\begin{tabular}{lccr}
\hline & Baseline & 6 Months & \multicolumn{1}{c}{$\begin{array}{c}\text { Difference } \\
\text { (Baseline- } \\
\text { 6 Months) }\end{array}$} \\
\hline Recession depth & $0.83 \pm 0.25$ & $0.84 \pm 0.27$ & $0.00 \pm 0.09$ \\
Recession width & $1.38 \pm 0.40$ & $1.46 \pm 0.43$ & $-0.08 \pm 0.17$ \\
Keratinized tissue & $4.70 \pm 0.70$ & $4.00 \pm 0.30$ & $0.70 \pm 0.76$ \\
Change in clinical & $7.89 \pm 0.39$ & $7.85 \pm 0.41$ & $0.04 \pm 0.10$ \\
$\quad$ attachment level & & & \\
Probing depth & $1.50 \pm 0.20$ & $1.50 \pm 0.20$ & $0.00 \pm 0.20$ \\
\hline
\end{tabular}

Changes in RD, RW, CAL, PD, and KT were not detected at any time interval throughout the treatment period (Table 5).

\section{Adverse Events}

One patient (PR) developed a mild swelling without exudate in the midfacial region (near the barrier) in the first week after surgery; this problem was successfully managed with antibiotics (amoxicillin $\$ 500 \mathrm{mg}$ q8h for 10 days). Another patient (TD) exhibited a non-adherent flap at the defect site at one week after surgery; the flap was resutured and the site healed uneventfully. No other adverse events were observed throughout the 6-month clinical trial.

\section{DISCUSSION}

Multiple approaches have been used to replace lost, damaged, or diseased gingival tissues. Recently, non-absorbable ePTFE membranes have been successfully used in gingival root coverage treatment based on the principle

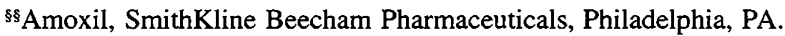

Table 3. Percentage of Root Coverage Calculated From Clinical Parameters (mean \pm standard error) at Different Time Periods $(\mathbf{n}=\mathbf{1 0})$

\begin{tabular}{lccccc}
\hline & 1 Week & 2 Weeks & 4 Weeks & 3 Months & 6 Months \\
\hline Recession depth & $0.84 \pm 0.20^{*}$ & $1.32 \pm 0.31 *$ & $1.53 \pm 0.26^{*}$ & $1.60 \pm 0.18^{*}$ & $1.53 \pm 0.22^{*}$ \\
Root coverage & $72.56 \pm 6.74$ & $59.53 \pm 8.54$ & $51.73 \pm 7.77$ & $49.04 \pm 5.69$ & $51.55 \pm 6.8$ \\
$\quad$ from baseline \% & & & & & \\
\hline
\end{tabular}

*Statistically significant difference $(P<0.05)$.

Table 4. Comparison of Gingival Index and Plaque Index Between Collagen-Treated and Non-Treated Adjacent Sites (mean \pm standard error) at Different Time Periods $(n=10)$

\begin{tabular}{lcccccc}
\hline & Baseline & 1 Week & 2 Weeks & 4 Weeks & 3 Months & 6 Months \\
\hline $\begin{array}{l}\text { Gingival Index } \\
\quad \text { Collagen }\end{array}$ & $0.3 \pm 0.2$ & $1.0 \pm 0.2$ & $0.9 \pm 0.2$ & $0.6 \pm 0.2$ & $0.3 \pm 0.2$ & $0.2 \pm 0.1$ \\
$\quad$ Adjacent site & $0.2 \pm 0.1$ & $0.2 \pm 0.1$ & $0.4 \pm 0.2$ & $0.1 \pm 0.1$ & $0.1 \pm 0.1$ & $0.2 \pm 0.1$ \\
Plaque Index & & & & & & \\
$\quad$ Collagen & $0.4 \pm 0.2$ & $0.0 \pm 0.0$ & $0.8 \pm 0.2$ & $0.8 \pm 0.2$ & $0.4 \pm 0.2$ & $0.1 \pm 0.1$ \\
Adjacent site & $0.1 \pm 0.1$ & $0.1 \pm 0.1$ & $0.5 \pm 0.2$ & $0.4 \pm 0.2$ & $0.1 \pm 0.1$ & $0.3 \pm 0.2$ \\
\hline
\end{tabular}


of guided tissue regeneration. ${ }^{8-17}$ However, these materials must be retrieved, necessitating a second surgical procedure which in itself may disrupt the process of regenerative healing. In addition, non-absorbable barriers have been associated with a relatively high incidence of membrane exposure ${ }^{37}$ that can result in unwanted colonization by oral bacteria, which may limit the amount of new attachment formed and induce further gingival recession. ${ }^{37,38}$ As outlined earlier, bioabsorbable barriers composed of materials such as type I collagen offer several advantages over non-absorbable membranes which may overcome many of these material-related deficiencies and reduce unwanted tissue-related problems.

Results obtained indicate that the GTR-collagen membrane-based root coverage techniques used here consistently resulted in a reduction of gingival recession and corresponding root coverage. A statistically significant mean reduction of $1.66 \mathrm{~mm}$ in RD was obtained after treatment, representing $51.6 \%$ of total attainable root coverage. In addition, a statistically significant mean gain of $1.34 \pm 0.47 \mathrm{~mm}$ CAL was also observed at 6 months post-treatment. These clinical results are similar to or slightly less than those reported for traditional grafting procedures such as free gingival grafts, laterally positioned flaps, coronally positioned flaps, and connective tissue grafts (i.e., approximately $36 \%$ to $80 \%$ of root coverage)..$^{39}$ However, these conventional techniques are often limited by the need for two surgical sites, availability of donor tissue, and a potentially unfavorable color and texture match at the recipient site after healing is complete. Therefore, procedures using the principle of GTR described here may offer the following advantages over these conventional techniques: elimination of the donor site requirement, surgery, and associated morbidity; reduction in operatory time required for donor tissue procurement; and availability of unlimited barrier material of a uniform thickness. However, future studies with controls are needed to test the true benefit of this newly developed GTR technique when compared to these conventional approaches.

These findings are also in agreement with an earlier study by Tinti et al. ${ }^{9}$ in which a mean reduction of 2.5 $\mathrm{mm}$ in RD and $55.2 \%$ root coverage was achieved using non-resorbable ePTFE membranes. Comparable and slightly better results (65\% of root coverage) were also demonstrated by Pini Prato et al. using a bioabsorbable barrierlll material. ${ }^{13}$ In this present report, gains in CAL were accompanied by reductions in recession depth, although the CAL gain was less than that reported by previous studies (ranging from 2.60 to $5.12 \mathrm{~mm}$ ). ${ }^{9.11,13-16} \mathrm{Sev}-$ eral studies have also reported a much higher percentage of root coverage, ranging from $67 \%$ to $83 \% .{ }^{11-17}$ These differences in outcomes are difficult to explain but may

III Guidor, Guidor USA, Bensenville, IL. be partially based on characteristics unique to these particular studies including the demographics of study participants, size of the defects treated, and measurement techniques employed. Other factors such as operator experience/surgical skills and the occurrence of a learning curve during the study may also account for the difference observed between the studies. The success of GTR therapy rests heavily upon individual patient factors such as root prominence, depth of the vestibule, soft tissue quality, and compliance during the postsurgical period; whether our small study population $(n=10)$ presented a normal distribution of these variables remains unknown. In addition, as reported by Pini Prato et al.," sites with deeper recession defects tend to respond more favorably than shallower sites. Sites selected for therapy in this study (average recession depth $=3.19 \mathrm{~mm}$ ) were less advanced than those used in the majority of previous studies (average recession depth $\geq 4.5 \mathrm{~mm}^{9-16}$ ). A major difference in reported outcomes can also occur if different measurement tools or protocols are used. In many earlier studies, ${ }^{11-17}$ recession measurements were taken with a manual probe (with a resolution to $1 \mathrm{~mm}$ ), in contrast to the Boley gauge technique (with resolution to $0.1 \mathrm{~mm}$ ) used here.

As reported earlier by Tinti et al. and Trombelli et al., using ePTFE membranes, we found no change in probing depths (PD) before and after recession therapy. ${ }^{9,16}$ Considering that root coverage was achieved in these situations, this finding illustrates a gain in clinical attachment and suggests formation of a new attachment on a portion of the covered root surface. In the absence of histological evidence, it is impossible to determine whether this gain in attachment is facilitated by formation of a long junctional epithelium, a new connective tissue attachment, or a combination of both types of healing. However, Cortellini et al.," ${ }^{21}$ using human histologic material, have previously shown that root coverage can be accompanied by formation of a new fibrous periodontal attachment. Obviously, additional studies are required to better understand the nature of the tissue interface between the newly covered root surface and overlying gingival tissues.

A statistically significant gain in keratinized tissue (KT: $0.9 \pm 0.32 \mathrm{~mm}$ ) was noted at 6 months postoperatively. The extent of KT obtained in the present study is comparable to that reported by Tinti et al. $(0.83 \pm 0.39 \mathrm{~mm}),{ }^{9}$ Pini Prato et al. $(0.56 \pm 0.2 \mathrm{~mm}),{ }^{11}$ and Trombelli et al. $(1.10 \pm 0.23 \mathrm{~mm})^{14}$ using ePTFE membranes. Pini Prato et al. also reported a gain of $0.66 \pm 0.29 \mathrm{~mm} \mathrm{KT}$ using PLA membranes. ${ }^{13}$ This increase in KT has been suggested to occur due to formation of new connective tissue. ${ }^{14}$ However, variations in clinical measurements could also contribute to the increase of KT since these are only recorded to the nearest millimeter.

Clinical parameters (i.e., PI and GI) remained relatively constant at all time intervals during the experimental pe- 
riod, suggesting that surgically positioned collagen membranes were well-tolerated by the host tissues. When treated teeth were compared to adjacent non-treated teeth, no increase in visually detectable plaque accumulation was found. This finding is in agreement with Blumenthal $^{24}$ and Wang et al. ${ }^{31}$ and Chen et al., ${ }^{32}$ who reported that placement of collagen membranes does not enhance plaque accumulation or gingival inflammation.

The creation and maintenance of a space between the root surface and the overlying GTR barrier is considered essential to the success of guided tissue regeneration therapy. This space is believed necessary to provide a channel for the migration of progenitor cells toward and onto the detoxified root surface ${ }^{29,40}$ where differentiation of cementoblasts and formation of a new cementum/PDL is desired. Unfortunately, space preservation in recession defects is often difficult to achieve because the morphology of the dehiscence tends to allow collapse of the membrane against the root surface. In previous studies, a variety of techniques have been used to create and maintain space along dehisced or exposed root surfaces; these methods have included grinding the root surface to a concave shape, bending or everting the membrane with sutures, ${ }^{12}$ injecting a thick film of fibrin/fibronectin sealing between the root surface and the membrane,,$^{14-16}$ and using titanium-reinforced ePTFE membranes. ${ }^{10}$ In the present study, it is possible that space was created not only through the "tenting" effect of the collagen barrier, but also at later timepoints of wound healing due to the degradation of the membrane. Initially, the barrier may create a protected space where clot formation and cellular proliferation $/ \mathrm{mi}$ gration can occur; later, a secondary space may be created as the barrier is degraded by host enzymes. When placed as a wetted material, the collagen barrier is $0.4 \mathrm{~mm}$ thick, and subsequent collagenolytic breakdown of the barrier may provide a comparable accessory space. It has been proposed that this "secondary space" may contribute to the regenerative response on the root side of the barrier ${ }^{26,27}$ or may cause an increase in the thickness of the gingival tissues as the barrier is replaced by host connective tissue. $^{41}$

This study must be interpreted with consideration to the following limitations: relatively small sample size (patient $\mathrm{n}=10$ ), short evaluation period, the influence of a learning curve during the study, and lack of a treatment control. A subsequent study using a larger sample size, experienced surgeons, an experimental design incorporating appropriate controls (e.g., a coronally positioned flap alone and/or a coronally positioned flap with subepithelial connective tissue graft), and a longer follow-up period (more than 12 months) is required and will be instituted. In addition, the formation of new periodontal attachment cannot be confirmed without accompanying histological evidence. The barrier may be acting as a GTR device or, alternatively, may be serving as a collagenous scaffold beneath the repositioned flap which facilitates wound healing or connective tissue adaptation (vs. attachment) to the root surface. Animal-based studies are being planned to determine the healing dynamics that accompany placement of a collagen membrane under these clinical conditions. However, within the limitations of this study, the following conclusions can be made: 1) use of a bioabsorbable collagen barrier material as a root coverage grafting material facilitates gingival coverage of recession defects; 2 ) root coverage averaged $51.6 \%$ and was accompanied by a gain in clinical attachment $(1.34 \mathrm{~mm})$; and 3) the collagen material used in this study was well-tolerated by gingival tissues and had no adverse effects on treated and adjacent non-treated sites.

\section{REFERENCES}

1. Grupe H, Warren R. Repair of gingival defects by a sliding flap operation. J Periodontol 1956;27:92-99.

2. Guinard EA, Caffesse RG. Treatment of localized gingival recessions. Part I. Lateral sliding flap. J Periodontol 1978;49:351-356.

3. Sullivan HC, Atkins JH. Free autogenous gingival grafts. III. Utilization of grafts in the treatment of gingival recession. Periodontics 1968;6:152-160.

4. Holbrook T, Ochsenbein C. Complete coverage of the denuded root surface with a one-stage gingival graft. Int J Periodontics Restorative Dent 1983;3:8-27.

5. Langer B, Langer L. Subepithelial connective tissue graft technique for root coverage. J Periodontol 1985;56:715-720.

6. Bouchard P, Etienne D, Ouhayoun J, Nilveus R. Subepithelial connective tissue grafts in the treatment of gingival recessions. A comparative study of 2 procedures. J Periodontol 1994;65:929-936.

7. Allen EP, Miller PD. Coronal positioning of existing gingiva: Shortterm results in the treatment of shallow marginal tissue recession. $J$ Periodontol 1989;60:316-319.

8. Cortellini P, Pini Prato G, DeSanctis M, Baldi C, Clauser C. Guided tissue regeneration procedure in the treatment of a bone dehiscence associated with a gingival recession: A case report. Int $J$ Periodontics Restorative Dent 1991;11:460-467.

9. Tinti C, Vincenzi G, Cortellini P, Pini Prato G, Clauser C. Guided tissue regeneration in the treatment of human facial recession. A 12-case report. J Periodontol 1992;63:554-560.

10. Tinti C, Vincenzi P. Expanded polytetrafluoroethylene titanium-reinforced membranes for regeneration of mucogingival recession defects. A 12-case report. J Periodontol 1994;65:1088-1094.

11. Pini Prato G, Tinti C, Vincenzi G, Magnani C, Cortellini P, Clauser C. Guided tissue regeneration versus mucogingival surgery in the treatment of human buccal gingival recession. J Periodontol 1992; 63:919-928.

12. Pini Prato G, Clauser C, Cortellini P. Guided tissue regeneration and a free gingival graft for the management of buccal recession: A case report. Int J Periodontics Restorative Dent 1993;13:487-493.

13. Pini Prato G, Clauser C, Magnani C, Cortellini P. Resorbable membranes in the treatment of human buccal recession: A nine-case report. Int J Periodontics Restorative Dent 1995;15:258-267.

14. Trombelli L, Schincaglia G, Checchi L, Calura G. Combined guided tissue regeneration, root conditioning, and fibrin-fibronectin system application in the treatment of gingival recession. A 15-case report. J Periodontol 1994;65:796-803.

15. Trombelli L, Schincaglia GP, Scapoli C, Calura G. Healing response of human buccal gingival recessions treated with expanded polytetrafluoroethylene membranes. A retrospective report. $J$ Periodontol $1995 ; 66: 14-22$. 
16. Trombelli L, Schincaglia GP, Zangari F, Griselli A, Scabbia A, Calura $\mathrm{G}$. Effects of tetracycline $\mathrm{HCl}$ conditioning and fibrin-fibronectin system application in the treatment of buccal gingival recession with guided tissue regeneration. J Periodontol 1995;66:313-320.

17. Roccuzzo M, Lungo M, Corrente G, Gandolfo S. Comparative study of a bioresorbable and a non-resorbable membrane in the treatment of human gingival recessions. J Periodontol 1996;67:7-14.

18. Wilderman MN, Wentz FM. Repair of a dentogingival defect with a pedicle flap. $J$ Periodontol 1965;35:218-231.

19. Gottlow J, Nyman S, Karring T, Lindhe J. Treatment of localized gingival recessions with coronally displaced flaps and citric acid. An experimental study in the dog. J Clin Periodontol 1986;13:57-63.

20. Cortellini P, DeSanctis M, Pini Prato G, Baldi C, Clauser C. Guided tissue regeneration procedure using a fibrin-fibronectin system in surgically induced recession in dogs. Int J Periodontics Restorative Dent 1991;11:150-163.

21. Cortellini P, Clauser C, Pini Prato G. Histologic assessment of new attachment following the treatment of a human buccal recession by means of a guided tissue regeneration procedure. $J$ Periodontol 1993;64:387-391.

22. Blumenthal $\mathrm{N}$, Steinberg $\mathrm{J}$. The use of collagen membrane barriers in conjunction with combined demineralized bone-collagen gel implants in human infrabony defects. J Periodontol 1990;61:319-327.

23. Chung KM, Salkin LM, Stein MD, Freedman AL. Clinical evaluation of a biodegradable collagen membrane in guided tissue regeneration. J Periodontol 1990;61:732-736.

24. Blumenthal NM. A clinical comparison of collagen membranes with e-PTFE membranes in the treatment of human mandibular buccal class II furcation defects. J Periodontol 1993;64:925-933.

25. Black BS, Gher ME, Sandifer JB, Fucini SE, Richardson AC. Comparative study of collagen and expanded polytetrafluoroethylene membranes in the treatment of human class II furcation defects. $J$ Periodontol 1994;65:598-604.

26. Blumenthal NM. The use of collagen membranes to guide regeneration of new connective tissue attachment in dogs. $J$ Periodontol 1988;59:830-836.

27. Pitaru S, Tal H, Soldinger M, Noff M. Collagen membranes prevent apical migration of epithelium and support new connective tissue attachment during periodontal wound healing in dogs. J Periodont Res 1989;24:247-253.

28. Wikesjo UME, Nilveus RE, Selvig KA. Significance of early healing events on periodontal repair. A review. J Periodontol 1992;63: 158-165.

29. Haney JM, Nilveus RE, McMillan PJ, Wikesjo UME. Periodontal repair in dogs: Expanded polytetrafluoroethylene barrier membranes support wound stabilization and enhance bone regeneration. $J$ Periodontol 1993;64:883-890.

30. Steinberg AD, LeBreton G, Willey R, Mukherjee S, Lipowski J. Extravascular clot formation and platelet activation on variously treated root surfaces. J Periodontol 1986;57:516-522.

31. Wang HL, O'Neal RB, Thomas CL, et al. Evaluation of an absorbable collagen membrane in treating class II furcation defects. $J$ Periodontol 1994;65:1029-1036.

32. Chen CC, Wang H-L, Smith F, Glickman J, Shyr Y, O'Neal R. Evaluation of a collagen membrane with and without bone grafts in treating periodontal infrabony defects. $J$ Periodontol $1995 ; 66$ :838847.

33. Postlethwaite AE, Seyer JM, Kang AH. Chemotactic attraction of human fibroblasts to type I, II, and III collagens and collagen-derived peptides. Proc Natl Acad Sci (USA) 1978;75:871-875.

34. Johns LP, Merritt K, Agarwal S, Ceravolo FJ. Immunogenicity of a bovine collagen membrane in guided tissue regeneration. $J$ Dent Res 1992;71 (Spec. Issue):298 (Abstr. 1538).

35. Silness J, Löe H. Periodontal disease in pregnancy. II. Correlation between oral hygiene and periodontal condition. Acta Odontol Scand 1964;22:121-135.

36. Löe $\mathrm{H}$. The gingival index, the plaque index and the retention index systems. J Periodontol 1967;38 (Suppl):610-616.

37. Selvig KA, Kersten BG, Chamberlain AD, Wikesjo UM, Nilveus RE. Regenerative surgery of intrabony periodontal defects using ePTFE barrier membranes: Scanning electron microscopic evaluation of retrieved membranes versus clinical healing. J Periodontol 1992;63:974-978.

38. Tempro PJ, Nalbandian J. Colonization of retrieved polytetrafluoroethylene membranes: Morphological and microbiological observations. J Periodontol 1993;64:162-168.

39. Egelberg J. Gingival grafting for coverage of denuded labial root surfaces. In: Egelberg J, ed. Periodontics. The Scientific Way. Synopses of Human Clinical Studies. Malmo, Sweden: OdontoScience; 1995:20.

40. Minabe M. A critical review of the biologic rationale for guided tissue regeneration. J Periodontol 1991;62:171-179.

41. Pitaru S, Tal H, Soldinger M, Grosskopf A, Noff M. Partial regeneration of periodontal tissues using collagen barriers. Initial observations in the canine. $J$ Periodontol 1988;59:380-386.

Send reprint requests to: Dr. Hom-Lay Wang, University of Michigan, School of Dentistry, 1011 N. University Ave., Ann Arbor, MI 481091078 .

Accepted for publication January 15, 1997. 